\title{
Penerapan Aspek Environmental Dalam Arsitektur Sustainable Pada Perancangan Stasiun Kereta Api Pekanbaru
}

\author{
Muhammad Rafi Ihsan ${ }^{1}$, Muhd. Arief Al Husaini², Muhammad Rijal ${ }^{3}$ \\ e-mail: muhammad.rafi4267@student.unri.ac.id ${ }^{1}$, muhd.arief@lecturer.unri.ac.id ${ }^{2}$ \\ Program Studi Arsitektur, Fakultas Teknik, Universitas Riau ${ }^{1,2,3}$
}

\begin{abstract}
Abstrak
Pekanbaru merupakan salah satu kota besar di Indonesia dengan jumlah mobilitas penduduk yang tinggi. Tetapi tidak diiringi dengan penyediaan sarana transportasi umum yang cepat dan ekonomis. Sarana transportasi umum yang tersedia di Pekanbaru yaitu bus dan travel dinilai cukup ekonomis, namun membutuhkan waktu yang relatif lama. Sedangkan sarana transportasi lainnya yaitu pesawat dinilai cepat tetapi kurang ekonomis. Oleh karena itu, dibutuhkan transportasi umum alternatif yang cukup ekonomis dan cepat, yaitu kereta api. Untuk memenuhi kebutuhan tersebut, dibutuhkan stasiun kereta api di Pekanbaru. Kondisi pembangunan di Pekanbaru yang semakin pesat dan padat dapat berdampak buruk terhadap lingkungan. Maka dibutuhkan pembangunan yang ramah lingkungan dan berkelanjutan dalam bentuk desain stasiun yang memenuhi aspek environmental dalam arsitektur Sustainable. Metode penelitian yang digunakan yaitu kualitatif berupa pengumpulan data lapangan dan studi literatur yang berkaitan dengan topik pembahasan.
\end{abstract}

Kata Kunci : Stasiun kereta api, Sustainable, Arsitektur Sustainable, Environmental

\section{Abstract}

Pekanbaru is one of the big cities in Indonesia with a high population mobility. However, the city is not accompanied by the provision of fast and economical public transportation. The common public transportation facilities which are available in Pekanbaru, namely buses and travel, are considered as a quite economical, but require a long time to travel. Meanwhile, other transportation facilities, namely planes, are considered fast but less economical. Therefore, an economical and fast alternative public transportation, namely train, is needed. To meet this need, a railway station is required in Pekanbaru. The development condition in Pekanbaru which are getting faster and denser can adversely affect the environment. So, environmentally friendly and sustainable development is needed in the form of station designs that meet environmental aspects in sustainable architecture. The research method used is qualitative in the form of field data collection and literature study related to the topic of discussion.

Keywords : Railway Station, Sustainable, Sustainable Architecture, Environmental

\section{Pendahuluan}


Pekanbaru merupakan salah satu kota besar di Indonesia dengan tingkat pertumbuhan penduduk yang tinggi. Hal ini disebabkan Pekanbaru merupakan kota yang memiliki potensi bisnis yang besar sehingga banyak para pendatang berkeinginan untuk bekerja dan menetap di kota tersebut (Rusyanto, 2018). Tingginya pertumbuhan penduduk Kota Pekanbaru menimbulkan kemacetan lalu lintas, karena tidak seimbangnya penyediaan fasilitas transportasi umum dengan jumlah penduduknya.

Pada musim libur, penduduk kota Pekanbaru lebih memilih menggunakan kendaraan pribadi untuk bepergian antar kota seperti ke Medan, Jambi, Sumatera Barat, dan sebagainya. Meskipun sudah tersedia bandara Internasional di kota Pekanbaru, sebagian penduduk lebih memilih bepergian menggunakan kendaraan pribadi karena lebih ekonomis. Beberapa penduduk juga memiliki aerofhobia (takut naik pesawat) sehingga lebih memilih menggunakan jalur darat. Oleh karena itu, dibutuhkan penyediaan fasilitas transportasi umum yang cepat, aman, dan ekonomis. Alternatif yang dapat digunakan adalah kereta api.

Kota Pekanbaru memiliki 12 kecamatan dan 58 kelurahan yang memiliki luas sekitar 640,43 $\mathrm{km}^{2}$. Luas tiap kecamatan di kota Pekanbaru dapat dilihat pada tabel 1.

Tabel 1. Data Penduduk Pekanbaru

\begin{tabular}{|l|c|c|c|}
\hline \multicolumn{1}{|c|}{ Kecamatan } & $\begin{array}{c}\text { Luas } \\
\text { Wilayah }\end{array}$ & $\begin{array}{c}\text { Jumlah } \\
\text { Penduduk }\end{array}$ & $\begin{array}{c}\text { Kepadatan } \\
\text { Penduduk }\end{array}$ \\
\hline Sukajadi & 3,76 & 57.116 & 15.190 \\
\hline Kota Pekanbaru & 2,26 & 34.330 & 15.190 \\
\hline Sail & 3,26 & 26.980 & 8.276 \\
\hline Limapuluh & 4,04 & 51.294 & 12.697 \\
\hline Senapelan & 6,65 & 44.955 & 6.760 \\
\hline Rumbai & 128.85 & 67.796 & 526 \\
\hline Bukit Raya & 22,05 & 101.345 & 4.596 \\
\hline Tampan & 59,81 & 174.996 & 2.926 \\
\hline $\begin{array}{l}\text { Marpoyan } \\
\text { Damai }\end{array}$ & 29,79 & 146.014 & 4.901 \\
\hline Tenayan Raya & 171,27 & 141.922 & 829 \\
\hline Payung Sekaki & 51,36 & 100.103 & 1.949 \\
\hline Rumbai Pesisir & 157,33 & 74.859 & 476 \\
\hline Jumlah & 640,43 & 1.021 .719 & 1.595 \\
\hline
\end{tabular}

Sumber: Disdukcapil Kota Pekanbaru, Pekanbaru Dalam Angka, 2014

Pada tabel 1 dapat dilihat perbandingan luas wilayah, jumlah penduduk, dan kepadatan penduduk dari setiap kecamatan yang ada di Pekanbaru. Kecamatan Payung Sekaki dengan luas $51,36 \mathrm{~km}^{2}$ dijadikan sebagai lokasi pembangunan stasiun kereta api. Hal ini disebabkan karena luas wilayah yang cukup besar dan kepadatan penduduk yang tidak terlalu tinggi. Infrastruktur seperti jalanan di Kecamatan Payung Sekaki juga memadai. Selain itu, terdapat terminal bus pada kecamatan ini sehingga memudahkan masyarakat di daerah sekitar menuju stasiun kereta api. (IV and Data, 1987) 
Menurut kamus besar bahasa Indonesia (KBBI) 2010, stasiun kereta api adalah tempat persinggahan dan perhentian sementara kereta api sebelum melanjutkan perjalanan, serta tempat para penumpang kereta api menunggu dan keluar masuk saat menggunakan sarana transportasi kereta api. Adanya pembangunan stasiun kereta api menyebabkan peningkatan aksebilitas dan mobilitas masyarakat, percepatan pengembangan wilayah, dan penambahan tenaga kerja.

Salah satu stasiun kereta api besar di Indonesia yaitu stasiun Bekasi. Stasiun ini merupakan stasiun kelas besar tipe C (stasiun operasi) yang dapat melayani antar kota. Stasiun Bekasi yang berada di jalan Ir. H. Juanda dengan ketinggian mencapai +19 meter terletak di jalur utama KA (kereta api) lintas jawa utara sehingga termasuk stasiun tersibuk yang memiliki berbagai tujuan di Jawa. Permasalahan yang terjadi di stasiun ini yaitu terganggunya aktifitas perjalanan kereta karena jumlah penumpang KA yang tidak sebanding dengan jumlah armada. Penambahan jumlah penumpang KA setiap hari mencapai $+1,2$ juta. Fasilitas stasiun juga kurang terawat. Area parkir kurang tertata dengan baik, jumlah tempat duduk sangat sedikit, serta kondisi udara di stasiun yang panas (Sutianto, 2015).

Pada masa pemerintahan Presiden Joko Widodo, hal yang difokuskan yaitu dalam pembangunan infrastruktur, salah satunya adalah pembangunan jalur rel kereta api di berbagai daerah di Indonesia. Di Sumatra, terdapat pembangunan jalur rel kereta api trans-Sumatra yang menghubungkan antar provinsi di Sumatra. Pembangunan jalur rel kereta ini dilaksanakan tidak hanya untuk mengatasi kemacetan kendaraan lalu lintas, tetapi juga untuk memudahkan laju perdagangan sehingga meningkatkan pertumbuhan ekonomi (Jonan, 2016).

Seiring dengan perkembangannya zaman, kebutuhan akan sumber daya alam pun semakin meningkat. Penggunaan sumber daya alam yang berlebihan akan berdampak buruk terhadap lingkungan. Kondisi lingkungan yang buruk menyebabkan penurunan kualitas kehidupan makhluk hidup dimasa kini maupun dimasa yang akan datang. Pembangunan yang berkelanjutan menjadi solusi untuk menanggapi permasalahan tersebut dengan cara meminimalisir dampak buruk terhadap lingkungan sekitar. salah satunya dalam bentuk desain stasiun kereta api dengan penerapan aspek environmental.

\section{Lokasi Perancangan}


Muhammad Rafi Ihsan, Muhd. Arief Al Husaini, Muhammad Rijal

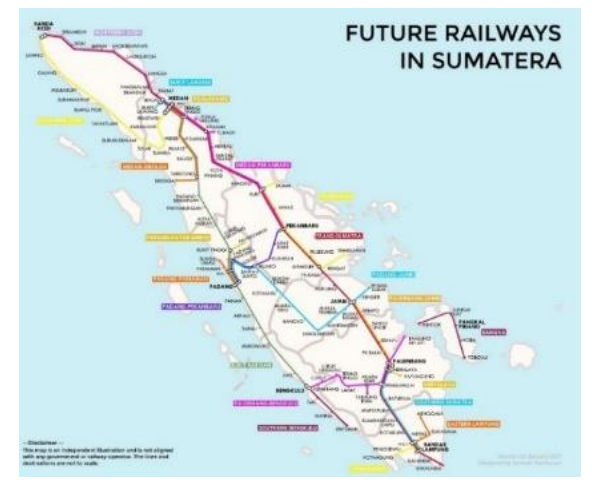

Gambar 1. Peta jalur kereta api Trans-Sumatra Sumber: Tambunan, Samuel

Stasiun kereta api berada di Kecamatan Payung Sekaki Kota Pekanbaru yang dirancang pada lokasi yang akan ditentukan sesuai dengan pertimbangan kondisi dan potensi tapak.

$\begin{array}{ll}\text { Luas Lahan } & : 40.000 \mathrm{~m}^{2} / 4 \text { ha } \\ \text { KDB } & : 50 \% \\ \text { Kontur } & : \text { Relatif datar } \\ \text { Kondisi Eksisting } & \text { : Lahan Kosong }\end{array}$

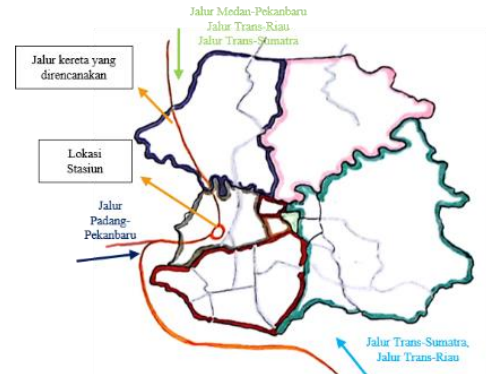

Gambar 2. Jalur kereta disekitar Pekanbaru

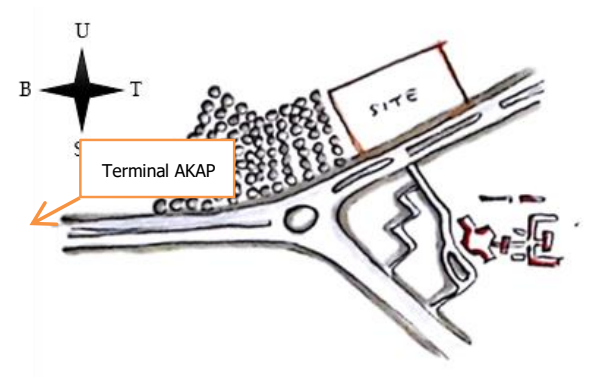

Gambar 3. Lokasi Stasiun kereta api

\section{Metode Penelitian}

Metode yang digunakan pada perancangan stasiun kereta api di Pekanbaru menggunakan metode kualitatif. Metode kualitatif merupakan suatu metode yang menggambarkan, menganalisa dan mengolah data dari penelitian yang telah ada. Analisis data secara kualitatif merupakan analisis yang dilakukan berdasarkan logika dan argumentasi. Beberapa cara dilakukan dengan analisis tapak 
untuk memperoleh data-data yang dibutuhkan dan studi banding yang berhubungan dengan objek rancangan.

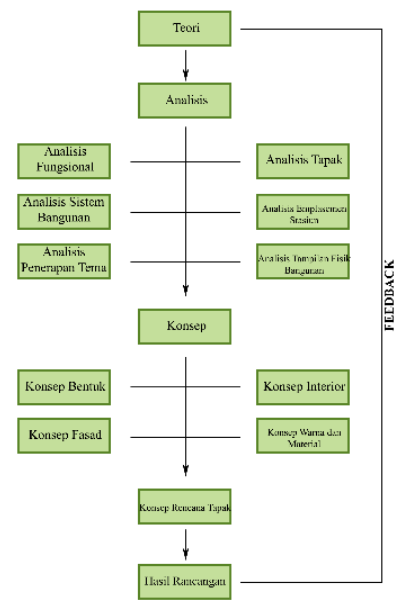

Gambar 4. Bagan Alur Perancangan

Penelitiaan dimulai dengan mengumpulkan landasan teori. Kemudian melakukan analisis yang terdiri dari analisis tapak, analisis fungsional, analisis sistem bangunan, analisis emplasemen stasiun, analisis penerapan tema, dan analisis tampilan fisik bangunan. Tahap berikutnya adalah menentuan konsep rancangan yang terdiri dari konsep bentuk, konsep fasad, konsep interior, serta konsep warna dan material. Setelah konsep rancangan ditentukan, didapatkan konsep rancangan tapak. Tahap akhir penelitian akan menghasilkan suatu rancangan.

\section{Hasil dan Pembahasan}

Stasiun adalah sebuah tempat pemberhentian dan pemberangkatan transportasi kereta api yang digunakan sebagai angkutan manusia maupun bongkar muat barang. Stasiun berupa tempat kereta api bersilang, menyusul, dan disusul. (Handinoto, 1999). Stasiun sebagai tempat kereta api berangkat, tempat pengangkutan manusia, binantang, maupun barang. (Handinoto, 1999). Bangunan Stasiun merupakan sebuah bangunan yang dijadikan untuk kebutuhan operasional kereta api yang terdiri dari Gedung, instalasi pendukung, dan peron.(Permenhub, 2011)

Stasiun kereta api memiliki beberapa jenis diantaranya: Stasiun berdasarkan tujuan (stasiun penumpang, stasiun barang, dan stasiun langsiran), Stasiun berdasarkan ukuran (stasiun kecil, stasiun sedang, dan stasiun besar), Stasiun berdasarkan posisi (Ground Level Station, dan Over Track Station, Under Track Station), Stasiun berdasarkan Kedudukan (stasiun awal, stasiun antara, stasiun akhir, dan stasiun pemeriksaan, dan stasiun batas perjalanan kereta api) dan Stasiun berdasarkan bentuk (stasiun siku-siku, stasiun parallel, stasiun pulau, stasiun semenanjung) 
Prinsip-prinsip desain stasiun kereta api meliputi: Ukuran dan penataan fasilitas, Sistem Informasi, Fasilitas umum, Lingkungan dan persyaratan kenyamanan, Desain untuk orang cacat, Fleksibilitas dan efisien ekonomi.

Bangunan stasiun kereta api memiliki beberapa persyaratan teknis yang telah ditetapkan (Permenhub, 2011) di antaranya sebagai berikut:

1. Bangunan Stasiun Kereta Api

Bangunan stasiun kereta api terdiri dari gedung stasiun, instalasi pendukung, dan peron.

A. Gedung Stasiun Kereta Api

Berdasarkan kegiatannya, gedung stasiun kereta api dibagi menjadi:

a. Gedung Stasiun untuk Kegiatan Pokok

b. Gedung stasiun untuk Kegiatan Usaha Penunjang

c. Gedung untuk Jasa Pelayanan Khusus

B. Instalasi dan Fasilitas Pendukung

Bangunan pelengkap untuk mendukung penyelenggaran perkeretapian dapat berupa konstruksi permanen, kontruksi besi ata baja, ataupun konstruksi sementara. Beberapa bangunan pelengkap di antaranya:

1. Jembatan Pemutar Lokomotif

2. Fasilitas untuk Kontainer atau Angkutan Barang

3. Depo Kereta Api

C. Peron

Peron yang berasal dari kata Belanda yaitu Perron, merupakan sebuah jalan kecil yang digunakan sebagai tempat keluar masuknya penumpang kereta api. Untuk menentukan lebar peron tergantung dari jumlah penumpang harian seperti pada perumusan sebagai berikut. (Aditya, 2020)

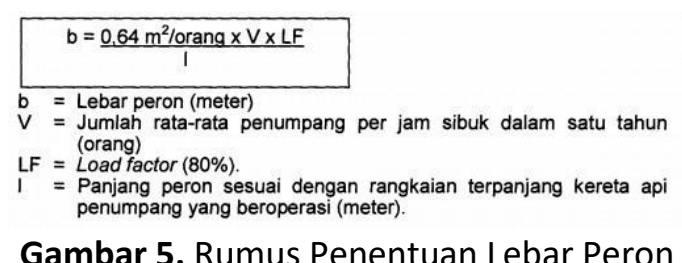

Sumber: PM. 29 tahun 2011

\section{Emplasemen Stasiun}

Emplasemen stasiun yaitu bagian dari stasiun yang berupa area terbuka yang terdiri dari susunan rel kereta api dengan kelengkapn-kelengkapan lainnya. Menurut Menteri perhubungan no. 29 tahun 2011, emplesemen stasiun terbagi menjadi tiga bagian utama di antaranya: 
1. Rel kereta api

Rel kereta api merupakan tempat menggerakkan atau memutar roda kereta api. Rel disebut juga sebagai jalurnya transportasi kereta api yang terdiri 2 batang rel kaku dengan ukuran yang sama panjang yang dipasang bantalan-bantalan yang dijadikan sebagai landasan kereta api. Tiap bantalan tersebut diikat menggunakan paku rel, penambat, atau sekrup penambat.

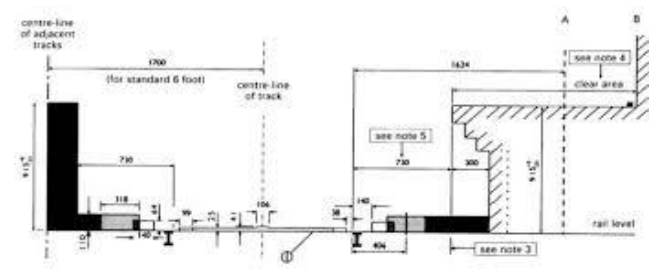

Gambar 6. Standar Batas Peron dan Rel Sumber: Data Arsitek, 2012

2. Fasilitas Pengoperasian kereta api

Menurut UU no 23 tahun 2007 fasilitas pengoperasian kereta api terdiri dari:

a. Peralatan persinyalan, fungsinya sebagai petunjuk dan pengarah yang berupa sinyal, tanda, dan marka.

b. Peralatan telekomunikasi, fungsinya sebagai penyampaian informasi dan komunikasi untuk kepentingan pengoperasian perkertaapian menggunakan frekuensi radio dan kabel yang telah ditetapkan dalam undang-undang di bidang telekomunikasi

c. Instalasi listrik, terdiri dari catu daya listrik yang berupa alat listrik yang membutuhkan sumber energi listrik unutk menghasilkan energi listrik yang ditransferkan ke perangkat listrik lainnya seperti menggerakkan kereta api menggunakan tenaga listrik, peralatan telekomunikasi, peralatan persinyalan, dan kelengkapan lainnya.

3. Drainase

Genangan air di rel kereta api mengganggu performa dan dapat menyebabkan kerusakan pada mesin karena korosi air. Saluran drainase tersebut dijaga dengan pemberian batu kerikil (Gravel) yang diletakkan dibawah bantalan rel kereta api dengan tujuan untuk mencegah adanya genangan air dibawah bantalan rel kereta api agar lebih terawatt dan terhindar dari korosi air.

Menurut (Utomo, 2009), perletakan jalur stasiun yang terdiri dari jalur rel-rel yang tersusun sesuai dengan fungsinya. Emplasemen memiliki beberapa jenis yaitu sebagai berikut.

1. Emplasemen Stasiun Kecil 
Emplasemen yang terdiri dari 2-3 rel kereta api dengan satu di antaranya berupa jalur rel terusan sedangkan satu atau dua lainnya sebagai rel persilangan atau bersusulan.

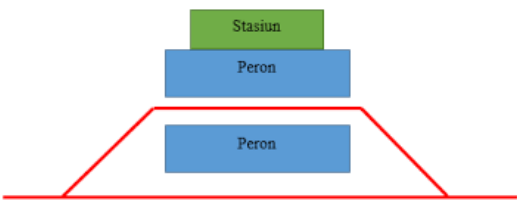

Gambar 7. Skema Emplasemen Stasiun Kecil

(Sumber: Utomo, 2009)

\section{Emplasemen Stasiun Sedang}

Emplasemen dengan jumlah relnya lebih banyak dibandingkan dengan emplasemen stasiun kecil.

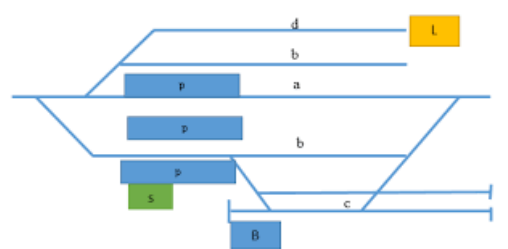

Gambar 8. Skema Emplasemen Stasiun Sedang (Sumber: Utomo, 2009)

\section{Emplasemen Stasiun Besar}

Posisi jalur rel stasiun besar tidak semuanya berdampingan, tetapi terdapat juga dalam bentuk perpanjangan. Pada stasiun besar, stasiun penumpang, stasiun barang, dan stasiun langsiran letaknya dipisahkan.
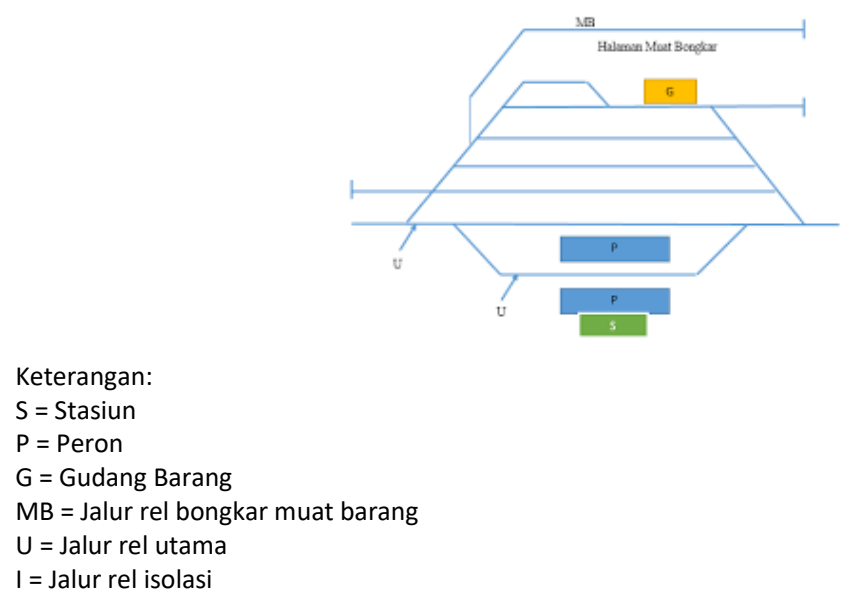

Gambar 9. Skema Emplasemen Stasiun Besar

(Sumber: Utomo, 2009)

\section{Emplasemen Barang}

Emplasemen barang dibuat khusus untuk pengiriman dan penerimaan barang. Emplasemen ini biasanya dibuat di wilayah industri, perdagangan ataupun pergudangan. 


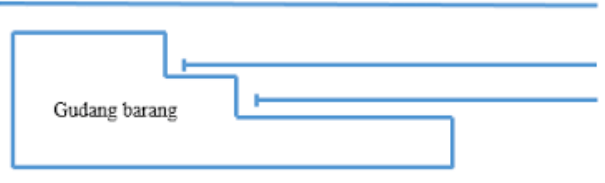

Gambar 10. Skema Emplasemen Barang Sumber: Utomo, 2009

5. Emplasemen Langsir

Emplasemen langsir dibuat untuk menyusun gerbong atau kereta yang akan ditarik dengan lokomotif. Umumnya kegiatan langsir terdiri dari:

a. Gerbong-gerbong yang datang dipisah (dipisahkan dari rangkaian kereta api)

b. Gerbong-gerbong setelah dipisah disesuaikan dengan jurusan yang dituju

c. Gerbong-gerbong Yang telah dipilih sesuai jurusannya dipilih dan digabungkan sesuai urutan stasiun yang akan dituju

d. Gerbong-gerbong yang telah dipilih sesuai jurusannya dan telah dipilih dan digabungkan sesuai urutan stasiun yang akan ditujunya dirangkai menjadi rangkaian kereta api yang akan dijalankan.

Fasilitas kegiatan yang diperlukan untuk memenuhi kebutuhan tersebut umumnya susunan emplasemen langsir terdiri dari beberapa sepur (jalur) meliputi susunan sepur kedatangan, susunan sepur keberangkatan, susunan sepur pemilihan jurusan, susunan sepur menurut stasiun.

Pada emplasemen langsir yang besar terdapat tiga bagian penempatan langsiran di antaranya langsiran kedatangan, langsiran pemisahan, langsiran pemilihan dan keberangkatan

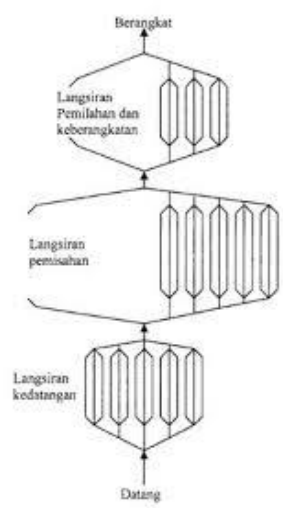

Gambar 11. Skema Emplasemen Langsir (Sumber: Utomo, 2009)

Berdasarkan penjelasan di atas, emplasemen stasiun besar menjadi pilihan dalam rancangan stasiun kereta api di Pekanbaru. Pekanbaru berada di lokasi yang strategis yakni di pertengahan pulau Sumatra yang banyak dilalui jalur lintasan antar kota. Selain itu, 
pemilihan emplasemen ini sesuai dengan rencana pemerintah untuk menyediakan jasa pengangkutan barang. Dengan demikian stasiun kereta api ini termasuk kawasan multimoda.

\section{Sustainable}

Sustainable adalah konsekuensi negatif dari produksi dan konsumsi sumber daya alam (Guenther dan Vittori, 2009). Sustainable memiliki prinsip-prinsip antara lain reduce, reuse, recycle, redesign, dan remanufacture (Jayal et al., 2010).

Sustainable Architecture atau disebut juga Arsitektur Berkelanjutan adalah sebuah konsep terapan di bidang arsitektur untuk memenuhi konsep berkelanjutan. Konsep ini mempertahankan sumber daya alam agar bertahan lebih lama, yang dikaitkan dengan umur potensi vital sumber daya alam, dan lingkungan ekologis manusia seperti iklim, kehutanan, pertanian, dan khususnya di bidang arsitektur (Kurniasih, 2010).

Perkembangan pembangunan berkelanjutan (Irsal, 2008) merupakan interaksi antara 3 sistem, yaitu sistem ekonomi, sistem lingkungan, dan sistem sosial. Dengan adanya kelengkapan ketiga konsep keberlanjutan tersebut maka pembangunan berkelanjutan akan lebih jelas dan bermakna dan terkait dengan masalah khusus di negara berkembang. Pada segi sosial, sasaran keberlanjutan akan lebih jelas dan terarah sehingga akan mengikatkan upaya pemerataan sosial (social equity), penanggulangan dan penghapusan kemiskinan (poverty eradication), keadilan spasial (spatial justice), dan sebagainya.

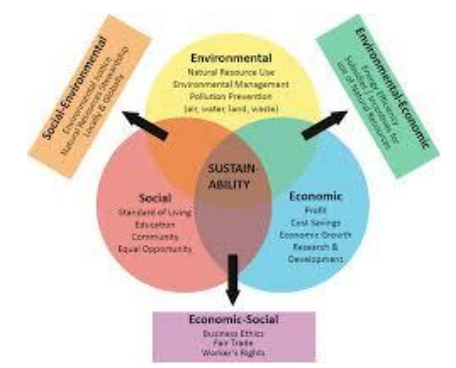

Gambar 12. Aspek Lingkungan, Ekonomi, Sosial Sumber: Jurnal SENTHONG, 2019

Konsep-konsep yang mendukung dalam arsitektur Sustainable yaitu Efisiensi Penggunaan Lahan, desain bangunan yang kontekstual dengan lingkungan sekitar, efisiensi penggunaan material, penggunaan teknologi dan material baru, dan bangunan hemat energi

Konsep bangunan hemat energi antara lain meminimalisir paparan panas matahari, orientasi bangunan menghadap utara-selatan, organisasi ruang, menghindari masuknya radiasi masuk ke dalam bangunan dan memaksimalkan pelepasan panas pada bangunan, mengoptimalisasi penggunaan ventilasi silang pada bangunan non-AC (Kurniasih, 2010). 


\section{Environment Sustainability}

Environmental Sustainability (Elleuch et al., 2018) dalam pendekatan arsitektur Sustainable yaitu Penggunaan sumber daya alam (Natural Resources Use), Pengelolaan lingkungan (Environment Management), Pencegahan polusi (Pollution Prevention).

Penerapan aspek environmental dalam arsitektur Sustainable pada perancangan stasiun kereta api di Pekanbaru terdapat pada tabel 2.

Tabel 2. Penerapan Aspek Environmental

\begin{tabular}{|c|c|c|}
\hline No. & $\begin{array}{c}\text { Aspek } \\
\text { Environmental }\end{array}$ & Penerapan \\
\hline 1. & $\begin{array}{l}\text { Penggunaan } \\
\text { Sumber Daya } \\
\text { Alam (Natural } \\
\text { Resources Use) }\end{array}$ & $\begin{array}{l}\text { Memaksimalkan bukaan } \\
\text { pada massa bangunan } \\
\text { sebagai pencahayaan } \\
\text { dan penghawaan alami, } \\
\text { pemanfaatan vegetasi } \\
\text { sebagai peneduh, } \\
\text { peredam kebisingan, } \\
\text { pemandangan }\end{array}$ \\
\hline 2. & $\begin{array}{l}\text { Pengelolaan } \\
\text { lingkungan } \\
\text { (Environment } \\
\text { Management) }\end{array}$ & $\begin{array}{l}\text { Pengolahan air hujan } \\
\text { yang akan digunakan } \\
\text { pada aktivitas di stasiun } \\
\text { kereta api. Olahan air } \\
\text { hujan yang berlebih } \\
\text { disalurkan ke tanah. }\end{array}$ \\
\hline 3. & $\begin{array}{l}\text { Pencegahan } \\
\text { Polusi }\end{array}$ & $\begin{array}{l}\text { Menggunakan material } \\
\text { hasil limbah berupa abu } \\
\text { terbang (fly ash) yang } \\
\text { akan dicampur dengan } \\
\text { material beton pada } \\
\text { dinding bangunan. }\end{array}$ \\
\hline
\end{tabular}

\section{Konsep}

Konsep dasar pada perancangan stasiun kereta api Pekanbaru berasal dari kata "Life Gap" yang berarti celah kehidupan. Celah berarti sela antara 2 objek dan dapat juga dikatakan sebagai sesuatu yang dapat digali atau dimanfaatkan. Celah kehidupan berarti memanfaatkan potensi di sekitar lingkungan. Potensi lingkungan tersebut diterapkan pada konsep bangunan.

Celah kehidupan dalam arsitektur Sustainable berarti memanfaatkan potensi lingkungan sekitar dengan cara diolah kemudian digunakan untuk beraktivitas.

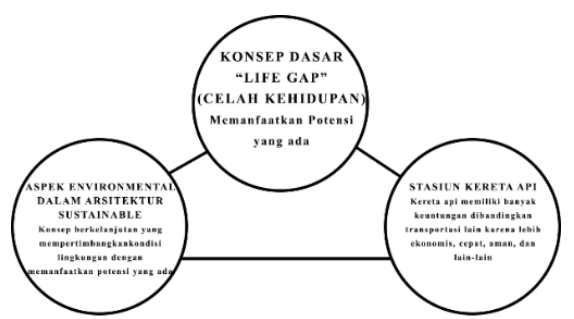

Gambar 13. Skema Konsep Life Gap 
Pada Gambar 13. diatas, terdapat skema hubungan antara konsep dasar, fungsi bangunan, dan tema rancangan yang memiliki tujuan yang sama dengan cara memanfaatkan potensi yang ada untuk menciptakan lingkungan menjadi lebih baik.

Bentuk dasar rancangan stasiun berasal kondisi lokasi dengan pemberian tanggapan lokasi. Kemudian penerapan konsep Life Gap pada dasar rancangan stasiun kereta api dengan memaksimalkan celah-celah pada bentuk bangunan untuk dimanfaatkan. Adapun transformasi desain pada gubahan massa bangunan stasiun dapat dilihat pada Gambar 11.
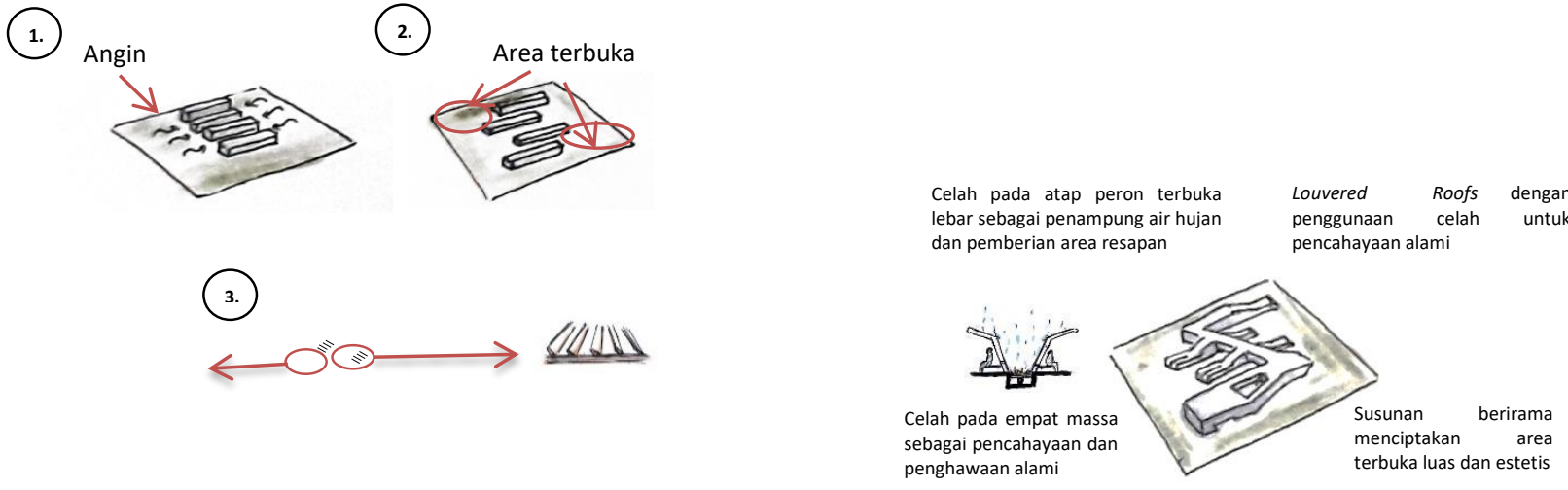

Gambar 14. Konsep Bentukan Massa

\section{Kesimpulan}

1. Penerapan aspek lingkungan dalam arsitektur Sustainable pada perancangan stasiun kereta api Pekanbaru diharapkan dapat memenuhi segala kebutuhan terhadap pengoperasian perkeretaapian.

2. Arsitektur Sustainable yaitu konsep terapan di bidang arsitektur untuk memenuhi konsep berkelanjutan yang berupa konsep mempertahankan sumber daya alam agar bertahan lebih lama, yang dikaitkan dengan umur potensi vital sumber daya alam dan lingkungan ekologis manusia seperti iklim planet, kehutanan, pertanian, dan khususnya di bidang arsitektur.

3. Perancangan Stasiun Kereta Api di Pekanbaru dirancang dengan tujuan untuk meminimalisir penggunaan SDA, dan sebagai fasilitas transportasi umum alternatif baru yang cepat, nyaman, dan ekonomis yang cocok untuk semua kalangan masyarakat khususnya di Pekanbaru.

\section{Daftar Pustaka}

Aditya (2020) 'Persyaratan Teknis Peron Stasiun Kereta Api'. Available at: https://keretapedia.com/2020/06/14/persyaratan-teknis-peron-stasiun-kereta-api/. Batiment, C. I. Du (1994) 'Definisi sustainable architecture'.

Booten, V. and Bulte (2000) 'No Title'. Available at: http://etheses.uinmalang.ac.id/1200/7/07660022_Bab_2.pdf. 
Elleuch, B. et al. (2018) 'Environmental sustainability and pollution prevention', Environmental Science and Pollution Research. Environmental Science and Pollution Research, 25(19), pp. 18223-18225. doi: 10.1007/s11356-017-0619-5.

Guenther, R. and Vittori, G. (2009) Sustainable architecture for health: a mindset shift. Available at: https://sci-hub.do/10.1177/193758670900200401.

Irsal, R. M. (2008) 'Perancangan Bangunan dengan Mempertimbangkan Aspek Energi dan Lingkungan Studi Kasus: Pengamatan Beberapa Bangunan di Jakarta dan Surabaya dengan Menggunakan LEED-NC 2.1', pp. 1-139. Available at: http://lib.ui.ac.id/file?file=digital/125206-050817.pdf.

Iv, B. a B. and Data, I. V. P. (1987) 'Bab iv pengumpulan dan pengolahan data', 1989(44), pp. 33-70. Jayal, A. et al. (2010) 'Sustainable manufacturing: Modeling and optimization challenges at the product, process and system levels', p. 1.

Jonan (2016) 'Reaktivasi Jalur Kereta Api Solusi Macet', (Reaktivasi Jalur Kereta Api Solusi Macet). Available at: https://www.jurnalasia.com/medan/reaktivasi-jalur-kereta-api-solusi-macetpengerjaan-dua-tol-trans-sumatera-dikebut/.

Kurniasih, S. (2010) 'SUSTAINABLE ARCHITECTURE'.

Permenhub (2011) 'Persyaratan teknis bangunan stasiun kereta api'. Available at: http://djka.dephub.go.id/uploads/201908/pm._no._29_tahun_2011.pdf.

Rusyanto, E. (2018) 'Pekanbaru Miliki Potensi Bisnis Besar'. Available at: https://www.beritasatu.com/ekonomi/501348/pekanbaru-miliki-potensi-bisnis-besar.

Soedirham, O. (2012) 'Sustainable'.

Sutianto, F. D. (2015) 'No Title', (Stasiun Bekasi, Potret Fasilitas Publik yang Baik?). Available at: https://www.kompasiana.com/febyunsoed/550d431a8133114322b1e32d/stasiun-bekasipotret-fasilitas-publik-yang-baik?page=all.

Utomo (2009) 'Emplasemen Kereta Api'. Available at: http://repository.umy.ac.id/bitstream/handle/123456789/14336/BAB

III.pdf?sequence=3\&isAllowed=y. 
Muhammad Rafi Ihsan, Muhd. Arief Al Husaini, Muhammad Rijal 